\title{
Uma proposta de leitura de poesia a partir do acervo do PNBE
}

\section{A proposal for poetry reading from the PNBE collection}

\author{
José Helder Pinheiro Alves ${ }^{1}$
}

\begin{abstract}
RESUMO
Pesquisas realizadas ao longo das três últimas décadas revelam que o trabalho com o poema no nível médio de ensino segue um padrão historicista que pouco contribui para a formação de leitores. Por outro lado, experimentos realizados em diferentes séries do ensino básico, lançando mão de uma metodologia de viés interacionista, têm como resultado um envolvimento efetivo do jovem leitor na construção dos sentidos do poema. Neste artigo, apresentaremos e discutiremos uma pesquisa voltada para o ensino de literatura no nível médio, bem como o resultado de um levantamento sobre o impacto do Programa Nacional Biblioteca da Escola (PNBE) no ensino de literatura em cinco escolas públicas de Campina Grande, Paraíba. Serão observados os possíveis usos do acervo deste importante programa de socialização de obras literárias no trabalho com o texto literário. Por fim, será apresentada uma proposta de abordagem de um dos livros de poemas selecionados para o acervo do PNBE - 2013. O intuito é, a partir de um diagnóstico das pesquisas sobre o trabalho com o poema e do aproveitamento (ou não) do acervo do PNBE no ensino médio, apontar algumas perspectivas metodológicas de trabalho com a poesia, privilegiando o diálogo texto-leitor. Fundamentamo-nos, sobretudo, nas contribuições acerca da Estética da Recepção, apostando em novas propostas metodológicas para o trabalho com o texto literário em sala de aula, notadamente o poema.
\end{abstract}

Palavras-chave: ensino de poesia; nível médio; PNBE.

DOI: $10.1590 / 0104-4060.36318$

1 Universidade Federal de Campina. Unidade Acadêmica de Letras. Campina Grande, Paraíba, Brasil. Rua Aprígio Veloso, 882. CEP 58429-900. 


\begin{abstract}
Researches during the last three decades reveal that the teaching of poems in High School follows a historicist pattern that does not contribute much to the reader development. Otherwise, experiments done in different grades of elementary teaching, using an interactionist methodology, showed an effective involvement of young readers in the construction of meaning when reading poems. In this paper, we are going to present and discuss a research about the teaching of literature in High School as well as the result of a survey about the impact of the School Library National Program (PNBE) in the teaching of literature in five public schools in Campina Grande, $\mathrm{Pa}$ raiba, Brazil. Possible uses of the collection of this important socialization program of literary works in the teaching of literary texts were observed. Finally, a text-approach proposal to one of the books of poems selected to the collection of PNBE - 2013 will be shown. From the research diagnostic about the teaching of poems and the use (or not) of the PNBE collection in High School, this research aims at pointing out some methodological perspectives of teaching poetry by giving emphasis to the text-reader dialogue. The theoretical framework used here is based on Reception Aesthetics, applying new methodological proposals to the teaching of literary texts in classrooms, particularly on poems.
\end{abstract}

Keywords: poetry teaching; High School; PNBE.

\title{
Introdução
}

\author{
Caminhos não há \\ Mas os pés na grama \\ os inventarão. \\ (Ferreira Gullar)
}

A problemática do ensino da literatura no nível médio vem sendo apontada e discutida há, pelo menos, quarenta anos entre nós. Inicialmente em estudos pontuais, como o de Osman Lins (1977). Embora não voltado para o Ensino Médio, o ensaio levanta e discute questões pertinentes ao ensino de literatura. A seguir, com uma pesquisa sobre conteúdos e metodologias de ensino, temos o trabalho de Maria Thereza Fraga Rocco (1981), que diagnostica questões que irão se agudizar, sobretudo, tendo em vista o crescimento da escola pública no final da década de 70 do século XX. No início da década de 1980, surge o livro 
Invasão da catedral, de Ligia Chiappini de Moraes Leite (1983)2, que enfrenta questões polêmicas e bastante atuais, como o problema do "manual didático", da metodologia de ensino (que deixa de lado qualquer participação do leitor no processo de ensino-aprendizagem) e questões de ordem político-econômica, como as condições de trabalho do professor, quase sempre impossibilitado de realizar uma formação permanente. Embora esses dois estudos tenham como foco a realidade de São Paulo, os problemas detectados têm um alcance nacional.

Outra obra que aborda o ensino de literatura é o livro Ensino de Literatura no $2^{\circ}$ grau: problemas \& perspectivas, de Letícia Malard (1985). Inicialmente a autora faz uma abordagem histórica, situando o ensino da literatura a partir do Império e apontando mudanças efetuadas desde o final do século XIX. Uma das contribuições da pesquisadora está em abordar a literatura como "uma prática social", entendida "no sentido de atividade humana em intenção transformadora do mundo, que expressa o peculiar da relação do homem com o mundo, os modos de ser do homem no mundo" (MALARD, 1985, p. 10). A perspectiva adotada foge, teoricamente, do modelo historicista e abre-se para uma metodologia que privilegia a interação texto-leitor. O livro ainda apresenta "alguns objetivos do ensino de literatura", "recursos para alcançar os objetivos", como também traz uma rápida discussão sobre a "função das disciplinas auxiliares" ao ensino de literatura, especificamente a Teoria da Literatura e a "história da literatura brasileira".

No final dos anos 1980 e ao longo dos anos de 1990, ainda no século passado, pesquisas mais pontuais surgem e contribuem para se ter um quadro mais amplo da problemática do ensino de literatura e da leitura literária em geral. Destaque-se, no final dos anos 80, o livro Literatura: a formação do leitor alternativas metodológicas, de Aguiar e Bordini (1988), em que a perspectiva metodológica assume um caráter definidor. Para as autoras,

Através de uma experiência de leitura acumulada e de posse de estratégias de ensino polemizantes, [o professor] pode promover um trabalho criativo, de sentido coletivo, encorajando os alunos a comentarem os textos do ponto de vista temático e formal e a cotejarem esses aspectos em obras de variada procedência histórica e geográfica, sem submeterem-se a eles como verdades definitivas (AGUIAR; BORDINI, 1988, p. 40).

2 Em 2005 a autora publica Reinvenção da catedral: Língua, literatura, comunicação, novas tecnologias e políticas de ensino, pela editora Cortez. A obra retoma alguns capítulos da anterior e amplia a reflexão sobre o ensino de literatura, sobretudo nos dois primeiros capítulos. 
A reflexão das pesquisadoras aponta para uma prática dialógica, em que está posta a necessidade de uma interação efetiva entre texto e leitor. É patente neste trabalho a influência da Estética da Recepção que se explicita no capítulo denominado "método recepcional". São apresentados no livro cinco métodos de abordagem do texto literário, todos tendo em comum a participação efetiva do leitor no processo de leitura. Os métodos não são instrumentos meramente facilitadores de leitura, antes, são procedimentos que favorecem uma leitura mais vertical das obras. Ao referir-se ao método recepcional, elas destacam que "a atividade de leitura fundada em pressupostos teóricos da Estética da Recepção deve enfatizar a chamada "obra difícil", uma vez que nela reside o poder de transformação de esquemas ideológicos passíveis de crítica" (p. 85).

A revista Gragoatá, do Instituto de Letras da Universidade Federal Fluminense, publicou, em 1997, um número denominado "O Ensino da Língua e da Literatura." Destacamos nesta edição os resultados de uma pesquisa realizada pela professora Gilda Neves da S. Bittencourt, denominada "O ensino da literatura no $2^{\circ}$. Grau: ótica do professor e do aluno". Inicialmente, ao problematizar o ensino da literatura, a autora faz perguntas ainda bastante pertinentes:

[...] como transformar uma manifestação essencialmente artística e intrinsecamente completa e indefinível, em objeto de estudo sistematizado, ao lado das ciências cujos contornos são mais delimitados e cujos modos de ser são mais facilmente identificados? Que método de abordagem utilizar num objeto de composição tão heterogêneo e que abre a inúmeras possibilidades de leitura? Tal multiplicidade na constituição da literatura tem desafiado a todos aqueles que tentam abordá-la sob uma perspectiva unívoca e como objeto de tessitura uniforme (1997, p. 260).

Embora não haja na pesquisa uma proposta metodológica, os dados levantados apontam para uma inquietação no que se refere ao enfrentamento do ensino da literatura. Para a pesquisadora, "Os problemas relativos ao ensino da literatura na escola [...] apresentam duas faces: a interna representada pelas dificuldades de defini-la como objeto de estudo sistemático e fixar uma metodologia de abordagem [...]". É mais precisamente a questão metodológica que nos interessa.

Outros autores e obras poderiam ser ainda apontados, como os importantes trabalhos voltados para o denominado letramento literário, a partir de pesquisas ligadas ao Centro de Alfabetização, Leitura e Escrita da Universidade Federal de Minas Gerais (Ceale-UFMG), com destaque para Letramento literário, de Rildo Cosson (2006), que traz uma importante discussão sobre a formação 
do leitor de literatura e apresenta modelos de propostas de sequência didática com o texto literário. A mais recente publicação no âmbito da reflexão sobre o ensino da literatura na escola é Leitura de Literatura na Escola, organizado por Dalvi, Rezende e Jover-Faleiros (2013). Como enfatizam as organizadoras, o livro "oferece material escrito de inegável singularidade para professores em formação inicial e continuada, pesquisadores e interessados nas questões teórico-epistemológicas, didático-metodológicas e ético-estéticas implicadas nas aproximações entre literatura e educação" (p. 15).

O início do século XXI foi marcado com a chegada dos Parâmetros Curriculares Nacionais - Ensino Médio. OS PCNs voltados para o ensino médio, em sua primeira versão, trazem uma abordagem do ensino de literatura bastante limitada, carecendo de, quando da publicação das Orientações Curriculares para o Ensino Médio - OCEM-2008, uma revisão cuidadosa da abordagem. Como avalia Rezende (2011, p. 280): “Os PCNEM de 2002 praticamente ignoraram a literatura e nenhuma contribuição trouxeram para o seu ensino, fazendo tábula rasa das discussões e pesquisas na área."

Em meio às dificuldades do ensino de literatura, algumas medidas foram tomadas pelo governo federal, visando minimizar o grave problema da formação precária de leitores em nossa escola. Merece destaque a criação do PNBE - Programa Nacional Biblioteca da Escola, que vem procurando suprir um problema grave: a tradicional ausência de obras literárias nas escolas públicas. E é sobre este programa que refletiremos a seguir.

\section{Sobre o PNBE}

O PNBE foi criado em 1997 e tem como objetivo principal, segundo Paiva (2012, p. 14), "democratizar o acesso a obras de literatura brasileira e estrangeira infantis e juvenis". Os livros são enviados às bibliotecas de escolas públicas de todo o país. A cada ano o programa contempla fases diferentes do ensino básico. Por exemplo, em 2010, o programa atendeu à Educação Infantil, Fundamental $\left(1^{\circ}\right.$ ao $5^{\circ}$ ano) e à Educação de Jovens e Adultos (EJA); em 2011, ao Ensino Fundamental ( $6^{\circ}$ ao $9^{\circ}$ ano) e ao Ensino Médio. O número de obras é bastante significativo, como se pode observar, a título de exemplo, pelos dados relativos ao acervo de 2012. Foram enviados três acervos para o Ensino Médio, cada um deles contendo 60 títulos ${ }^{3}$.

3 O Programa Nacional Biblioteca da Escola (PNBE) é executado pelo Fundo Nacional de Desenvolvimento da Educação (FNDE). Suas listas de seleção de obras são divulgadas no site: $<$ http://www.fnde.gov.br/index.php/ progrmama-da-escola $>$. 
Como lembra Paiva (2012, p. 15), refletindo sobre o PNBE, cada acervo é composto por

diversos gêneros literários, como: antologias poéticas brasileiras; antologias de crônicas; novelas ou romances brasileiros e estrangeiros (adaptados ou não); peças teatrais brasileiras e estrangeiras; obras ou antologias de textos de tradição popular brasileira, ensaios sobre um aspecto da realidade brasileira; biografias ou relatos de viagem.

Um aspecto a ser destacado é que, em meio a esta rica diversidade, predomina no acervo o gênero narrativo. Uma pequena constatação nos três acervos do Ensino Médio 2012: das 180 obras, temos apenas 30 livros de poemas.

O estudo de um possível impacto desta política de distribuição de obras ainda não foi feito em nível nacional. No entanto, duas obras resultantes de pesquisas sobre o PNBE na escola trazem dados e reflexões importantes. Em Literatura fora da caixa: o PNBE na escola-Distribuição, circulação e leitura, Paiva (2012) chama a atenção para o fato de que

Quando se investigam a visibilidade, o grau de conhecimento, a capilaridade dessas políticas no chão da escola, desconsiderando em que medida e de que maneira esses materiais são recebidos e usados pelos profissionais da escola, esvazia-se uma ação que poderia repercutir enormemente no processo de formação de leitores. Desse modo, nossa primeira iniciativa deve ser a divulgação da política e a insistência cotidiana para que os profissionais responsáveis pelo processo de formação de leitores dela se apropriem (p. 17).

Noutras palavras, as obras chegam à escola mas, na grande maioria das vezes, não há um trabalho de formação de leitores e nem, anteriormente, um trabalho de formação de mediadores. Decorrente desta situação (ou consequência dela), o fato é que os acervos são quase sempre desconhecidos dos professores dos diversos níveis de ensino. No nível fundamental ainda há um aproveitamento mínimo dessas obras em muitas escolas.

Outro trabalho que se volta para o acervo do PNBE é o livro Literatura e ensino médio: acervos, gêneros e práticas, organizado por Paiva, Souza e Corrêa (2011). Os autores tratam de diferentes gêneros, como a poesia, o romance, a 
crônica, dentre outros. Apenas um artigo retoma o acervo do PNBE 2009 para fazer algumas propostas de abordagem em sala de aula. Os demais avaliam a qualidade e a riqueza da diversidade das obras escolhidas.

No contexto do estado da Paraíba (Brasil), e, mais especificamente da cidade de Campina Grande, a partir de uma avaliação da presença do acervo do PNBE em cinco escolas, observou-se que os livros chegam, mas não há um projeto visando um aproveitamento mais efetivo das obras. Mesmo assim, muitos alunos procuram as salas de leitura para tomar livros emprestados, embora não haja, sistematicamente, orientação dos professores para uso do material. Outro dado significativo: de quinze professores indagados se conheciam o PNBE e se indicavam as obras para leitura, dez afirmaram não conhecer o programa, três conheciam, mas não utilizavam o acervo e apenas dois professores conheciam e indicavam as obras para leitura dos alunos ${ }^{4}$. Um desafio que se coloca, portanto, é refletir sobre possíveis caminhos que poderão ser trilhados na escola com o objetivo de, pelo menos, minimizar o problema. Neste sentido se faz necessário conhecer e colocar em prática os pressupostos de um documento fundamental que são as OCEM-2006.

\section{Propondo alguns caminhos}

A discussão, nesse item do texto, e as posteriores sugestões apresentadas estão em sintonia com as OCEM (BRASIL, 2008) e com pesquisas voltadas para metodologias de ensino que fogem da tradicional abordagem historiográfica do texto literário. O objetivo final é formar leitores. Conforme o documento:

A lacuna no contato direto com a Literatura percebida no ensino médio leva a considerações sobre as escolhas, já que os três anos da escolaridade e a carga horária da disciplina demandam uma seleção que permita uma formação o mais significativa possível para os alunos (BRASIL, 2008, p. 64).

4 Estes são dados preliminares de um Projeto de Pesquisa denominado Literatura no Ensino Médio e os acervos do PNBE: estudo das obras e propostas metodológicas, ligado ao Mestrado em Linguagem e Ensino da Universidade Federal de Campina Grande, PB (Brasil). A pesquisa está em fase inicial, tendo sido feito um levantamento da presença de acervos do PNBE em cinco escolas públicas do município de Campina Grande e feitas entrevistas com 15 professores do ensino fundamental e médio. 
Por outro lado, a questão central, na visão do documento, não é tão somente os conteúdos, e sim a metodologia utilizada:

Formar para o gosto literário, conhecer a tradição literária local e oferecer instrumentos para uma penetração mais aguda nas obras - tradicionalmente objetivos da escola em relação à literatura - decerto supõem percorrer o arco que vai do leitor vítima ao leitor crítico. Tais objetivos são, portanto, inteiramente pertinentes e inquestionáveis, mas questionados devem ser os métodos que têm sido utilizados para esses fins (BRASIL, 2008, p. 69).

O que se coloca é bastante complexo: pensar metodologias que possam contribuir para uma formação de leitores críticos e criativos. Muitos são os caminhos que vêm sendo trilhados e quase todos apontam para a necessidade de uma aproximação mais efetiva com o texto, aspecto que em si pressupõe aulas mais participativas e menos expositivas. Refletindo sobre esta questão, Pinheiro (2001) não se prende apenas ao viés metodológico, antes, indica a necessidade de uma mudança no plano do conteúdo. Para o professor:

Partimos do princípio de que antes de estudar teorias ou conhecer panoramas históricos, o jovem precisa ter uma experiência de leitura prazerosa e significativa. Isto é possível quando o jovem leitor se sente representado de algum modo nas obras que lê para poder atribuir sentidos à sua leitura. [...] O que propomos, de certo modo, dispensa o uso do manual. Trata-se de privilegiar a leitura das obras. Não há nada de mais em ler um capítulo de um livro em sala de aula. Perde-se às vezes tanto tempo repetindo conceitos, traços de estilos de época, resolvendo questões de interpretação (PINHEIRO, 2001, p. 21-22).

Rezende (2011, p. 291) aponta um caminho que ratifica a necessidade de uma postura diferenciada do ponto de vista metodológico. Trata-se de

Considerar a heterogeneidade, as experiências diversas, as particularidades culturais dos jovens e com elas dialogar [o que] não significa abandonar as obras universais da literatura nem os clássicos nacionais, tampouco esquecer o conhecimento, o refinamento da sensibilidade que tais obras propiciam, mas significa que o preenchimento de sentido suposto em todas essas atividades exige que se reconheça a voz dos jovens 
e que esses jovens já não aprendem só por meio da escola, que esta é apenas uma das formas de aquisição de saber no mundo contemporâneo. Às vezes surpreendemo-nos quando paramos para ouvi-los de verdade.

Pesquisas realizadas com alunos do Ensino Médio, utilizando uma metodologia que privilegia o diálogo leitor $\mathrm{x}$ texto, revelam que os jovens leitores, quando instados a se pronunciarem, a discutir diferentes questões postas nos textos literários, respondem de modo às vezes surpreendente, como assinalou Rezende.

Trabalhando com uma professora no primeiro ano do Ensino Médio, numa escola pública de Lagoa Seca, PB, a pesquisadora Patrícia Faria de Sousa (2013) realizou um experimento com poemas da poetisa Alice Ruiz lançando mão de uma perspectiva teórica calcada na valorização da voz do leitor, na sua convivência com o poema, no poder dizer sua palavra sobre os poemas lidos. Foram trabalhadas duas antologias contendo cerca de 16 poemas. Os poemas abordavam temas que estavam próximos do horizonte de expectativa dos jovens leitores. $\mathrm{O}$ fato de a poetisa também ser letrista de canções populares estimulou bastante a turma a buscar suas letras/canções para discutirem em sala de aula. Quanto aos resultados, como afirma a pesquisadora, os "alunos também estabeleceram pontes entre os saberes que trazem, por exemplo, do plano afetivo, como elucida Tardif (2010). Ou seja, os leitores articularam os poemas lidos à sua vivência afetiva, a seus conflitos, desejos e sentimentos. Observamos também que houve uma centralidade no diálogo texto-leitor [...] (SOUSA, 2013, p. 114). A experiência culminou com a realização de um sarau com leitura de poemas de Alice Ruiz, atividade que envolveu toda a escola. No entanto, o sarau não foi pensado $a$ priori, foi resultado de um percurso de mais de um mês de vivência com o texto poético. A pesquisadora destaca um dos momentos desta vivência, quando os alunos, após a leitura de alguns poemas da antologia, também ouviram a canção:

Outro momento significativo foi quando os alunos cantaram as músicas de Alice Ruiz. A primeira canção que ouviram foi "Socorro" na voz de Arnaldo Antunes. Acompanhando a letra pela antologia; os educandos foram, aos poucos, ouvindo e depois começaram a cantar e a bater palmas. Em seguida, ouviram e cantaram também "Quase nada" interpretada por Zeca Baleiro; nesse momento os alunos até "bailaram". É difícil descrever aquele momento, mas podemos dizer que era um modo diferente de experimentar a poesia, mais corporal, mais coletivo (SOUSA, 2013, p. 111).

5 A consulta à dissertação pode ser realizada no seguinte endereço: $<$ http://www.ual.ufcg. edu.br/posle/docs/arquivos/dissertacoes/2013/Patricia_de_Farias_Sousa.pdf $>$. 
Essas rápidas indicações mostram que é possível realizar um trabalho com o poema visando um envolvimento mais significativo com o texto, fugindo do modo tradicional de ensinar um saber sobre literatura, centrando-se na vivência corporal dos poemas.

\section{Trabalhando com poemas de Mario Quintana}

Poucas vezes enfrentamos a questão metodológica de modo mais direto, apresentando possibilidades de abordagem do texto que fujam ao modelo que ficou consagrado pelo livro didático: questões de interpretação - de múltipla escolha ou para dissertar, trazendo ao final uma interpretação de caráter fechado. Com este procedimento o aluno não tem nem sequer a possibilidade de apontar alguma reação pessoal diante da obra. ${ }^{6}$ Nos deteremos numa obra do acervo que estava prevista para ser entregue pelo MEC às escolas públicas em 2013, mais especificamente, um livro de poemas. Indicaremos alguns procedimentos que poderiam estimular o trabalho do professor em sala de aula. A obra escolhida foi Os melhores poemas de Mario Quintana, organizada pelo crítico Fausto Cunha. $\mathrm{Na}$ introdução do livro, Fausto Cunha aponta alguns eixos temáticos da lírica de Quintana: “o poeta fala da poesia, o poeta fala da paisagem, o poeta sorri, o poeta canta..." (1988, p. 11). Embora se possa partir da indicação do crítico, o mais adequado, do ponto de vista de uma metodologia que privilegie a relação mais próxima do leitor com o texto, não é seguir um conjunto de temas previamente apontados por um crítico ou professor, mas ir descobrindo os temas que suscitem interesse no leitor ao longo da leitura.

Que perspectiva de abordagem poderia ser trilhada num eventual trabalho em sala de aula com o livro de Quintana? Levantaremos algumas possibilidades, sempre certos de que cada turma, cada contexto é que deve presidir os caminhos a serem trilhados. Poder-se-ia iniciar discutindo os cinco primeiros poemas da obra os quais ostentam um viés metalinguístico. Mas não achamos viável começar definindo o que é metalinguagem. Deixar que os leitores se apercebam do que o poeta está falando, de como o eu lírico vê e sente a poesia, da função que atribui a ela e atentar para as comparações que ele escolhe para denominá-la.

A leitura oral dos poemas, repetidas vezes, é sempre um procedimento que favorece a descoberta de aspectos do poema que ficaram à sombra com as

6 Discutimos sobre o livro didático de literatura em Pinheiro (2006), onde apontamos seus principais problemas como o conteúdo enciclopédico, a presença diminuta de textos literários, o uso do texto para justificar a filiação a um estilo de época, dentre outras questões. 
primeiras leituras. Através da realização oral o leitor vai se aproximando do ritmo, do andamento do poema, vai se apercebendo de determinadas imagens que passam despercebidas a uma primeira leitura. Em vivência com o poema "Ah, sim, a velha poesia" em sala de aula do nível médio e no primeiro ano do curso de Letras, é comum os leitores destacarem: a) o modo afetuoso do poeta se dirigir à poesia ("Poesia, minha velha amiga..."); b) os objetos que o eu lírico "entrega" à poesia ("tudo/ a que os outros não dão importância nenhuma"); c) uma certa perplexidade ante o "sabor total" resultante desta entrega ("eternamente esse gosto de nunca e de sempre").

O percurso seguido é marcado - além da leitura oral feita pelo menos três vezes - pelo estímulo para que o leitor expresse sua reação ao poema: versos de que mais gostou ou que achou incompreensíveis; possíveis ligações com a experiência pessoal; tentativa de dar sentido a determinadas imagens (por exemplo, os grilos sempre geram hipóteses estimulantes), dentre outras inquietações. É necessário, neste percurso, favorecer uma experiência de troca, de liberdade para o leitor poder expor com tranquilidade suas percepções, o que não significa aceitar qualquer hipótese de interpretação. Há também que se destacar que a função do professor, nesse modelo de trabalho, é a de mediador e pressupõe questionar possíveis desvios graves de atribuição de sentido, sempre fazendo com que o leitor volte ao texto para comprovar suas hipóteses.

A partir da reflexão que o poeta faz sobre a poesia é possível atentar para outros temas que lhe são caros. Por exemplo, em "Aula inaugural" está posto o tema da dança - que no referido poema assume um papel central diante da vida ("Dança, pois, teu desespero, dança./ Tua miséria, teus arrebatamentos,/ Teus júbilos / [...] Dança com David diante da Arca da Aliança;/ [...] Dança diante da tua cova."). Em que sentido pode-se afirmar que "A poesia é a dança e a dança é alegria"? Que outros poemas da antologia abordam ou mesmo encenam o tema da dança? Esses poemas podem ser dançados - encenados no contexto escolar? Especificamente neste ponto, deve-se estimular o diálogo entre a literatura e outras artes. Veja-se, por exemplo, "Canção de domingo" (p. 33), "Inscrição para uma lareira" (p. 105) e a "Canção da primavera" (inicia-se com o verso "Primavera cruza o rio..." e que não consta na antologia)7. Já em "O poema" (p. 22), pode-se estimular o leitor a observar as comparações cunhadas para falar dele e pensar essa "misteriosa condição do poema". Não se trata de fornecer interpretações, mas de atuar como mediador, como alguém que estimula o outro a descobrir sentidos novos nos poemas e também a cultivar um certo

7 Uma sugestão a ser trabalhada é trazer a série de quadros de bailarinas do pintor francês Edgar Degas e pesquisar quadros de pintores brasileiros sobre o motivo da dança. Esse trabalho pode ser feito em parceria com outros professores, como o de história e o de artes. 
encantamento diante das imagens criadas - que nem sempre sabemos interpretar. Pode-se também trazer outros poemas para apreciação e/ou comparação, como "Os poemas", de Esconderijos do tempo, cujas imagens recolhidas para definir a poesia revelam uma delicadeza singular:

\author{
Os poemas são pássaros que chegam \\ não se sabe de onde e pousam \\ no livro que lês. \\ Quando fechas o livro, eles alçam vôo \\ como de um alçapão. \\ Eles não têm pouso \\ nem porto \\ alimentam-se um instante em cada par de mãos \\ e partem. \\ E olhas, então, essas tuas mãos vazias, \\ no maravilhado espanto de saberes \\ que o alimento deles já estava em ti...
}

Muitos leitores, diante deste poema, destacam a sonoridade advinda, por exemplo, da aliteração do /p/, bem como a concepção de que a poesia não está apenas no texto, ela só se realiza com o gesto do leitor que se propõe a abrir o livro. O leitor alimenta o pássaro, portanto, ele é fundamental na atribuição de sentido ao texto. Esta visão está em consonância com o que temos apontado como uma relação mais dialógica entre leitor e texto.

O tópico da antologia denominado "Espelho mágico" traz algumas quadras do livro de mesmo título ${ }^{8}$. Há aqui bem mais do que uma "autoajuda", como se tem lido alguns poemas de Quintana. Destaquem-se as observações agudas do poeta sobre a condição humana ("Dos hóspedes", p. 81), sobre a poesia ("Do estilo", p. 79); a observação sobre os males sociais ("Da humana condição", p. 81) e ainda sobre os amores ("Do amoroso esquecimento", p. 81), tudo abordado com bom humor e certa dose de ironia.

Outro procedimento a ser realizado - mas depois de várias experiências de leitura compartilhada (COLOMER, 2007) dos poemas em sala de aula - é deter-se mais analiticamente sobre alguns deles. "Tão lenta serena e bela" se-

8 Espelho mágico é o quarto livro de poemas de Mario Quintana, composto por 111 quadras sobre temas os mais diversos. O livro integralmente é publicado no volume denominado Poesias, de Mario Quintana (1989). 
ria um bom exemplo para uma leitura mais verticalizada. Observar o ritmo do poema, o andamento dos versos iniciais que parecem mimetizar a passagem lenta da vaca; atentar para os diferentes sentidos (visão, audição, tato, paladar e olfato) acionados no poema e que apontam para um certo modo de apreender as experiências. As imagens convidam a reflexões bem pontuais sobre a natureza e a cultura. Algumas perguntas poderão ajudar o leitor a verticalizar a experiência com o poema: por que a negatividade ante os "truques mecânicos"? Trata-se de uma postura contra o progresso? Se sim ou se não, em que sentido? Por que os alambrados, embora também mecânicos, são vistos no mesmo plano dos objetos naturais? A imagem da vaca pode ser lida como símbolo de alguma coisa ou de um modo de experimentar o tempo?

Poemas como "Inscrição para uma lareira" e "Pequeno poema didático" poderiam render boas descobertas sobre nuances às vezes deixadas de lado até pelos grandes críticos quando da avaliação da obra do poeta. Com relação aos dois poemas citados, atentar para a concepção que o poeta tem do tempo. Estimular os alunos a localizarem outros poemas que trazem imagens do tempo. Comparar, a posteriori, esta concepção com um fragmento do pensamento do filósofo grego Epicuro, sobre a passagem do tempo e as amizades, como por exemplo os fragmentos:

1. Quem menos sente a necessidade do amanhã mais alegremente se prepara para o amanhã. (EPICURO, apud ALVES, 2000, p. 139)

2. De todas as coisas que nos oferece a sabedoria para a felicidade de toda a vida, a maior é a aquisição da amizade. (EPICURO, apud ALVES, 2000, p. 142)

Outro tema de destaque na poesia de Quintana é o da morte, embora não predomine na antologia em destaque. Exemplares desta abordagem são os sonetos "Este quarto" (p. 55) e "Quando eu morrer" (p. 116). É recomendável discutir com os alunos a visão que o poeta tem da morte. Trata-se de uma visão religiosa, ligada a algum credo específico? Uma visão um tanto panteísta? Uma visão desencantada, de quem não cultivou a fé? Uma visão brincalhona, às vezes irônica? Aqui também a aproximação com a filosofia epicurista pode render boas discussões. Para o filósofo, devemos nos habituar a pensar que a morte "nada é para nós, visto que todo o mal e todo o bem se encontra na sensibilidade, e a morte é a privação da sensibilidade.” (EPICURO, apud ALVES, 2000, p. 143).

Em trabalho com alunos do Ensino Médio, após a leitura e discussão de vários poemas, também é interessante pensar um pouco nas questões formais. 
Por exemplo, temos na antologia "canções", sonetos, poemas metrificados, poemas em verso livre. Não se trata de ministrar aulas sobre teoria do verso, mas de observar, a partir da leitura, as diferenças entre um verso curto e um verso mais longo. Por exemplo, os versos de sete sílabas (redondilha maior), presentes em boa parte das canções, não podem ser lidos no mesmo andamento de versos de dez sílabas. A leitura dos dois fragmentos abaixo exemplifica esta questão:

\author{
Não quero a negra desnuda. \\ Não quero o baú do morto. \\ Eu quero o mapa das nuvens \\ E um barco bem vagaroso \\ (“Canção do barco e do olvido", 1988, p. 32) \\ O dia abriu seu pára-sol-bordado \\ De nuvens e de verde ramaria. \\ E estava até um fumo, que subia, \\ Mi-nu-ci-o-sa-men-te desenhado. \\ (“O dia abriu...", 1988, p. 45)
}

Estimula-se o aluno a perceber que o primeiro fragmento, em versos de sete sílabas, deve ser lido num andamento mais rápido e o segundo exemplo, em decassílabo, pede uma leitura mais pausada, numa cadência diferente. Oralmente, pode-se ler várias vezes tentando realizar essa diferença.

Entrando mais detidamente em questões formais, instiga-se a descobrirem possíveis diferenças entre "Canções" e "Sonetos". Aspectos voltados para a forma? O tamanho dos versos? Modo de abordagem, etc. Discutem-se também os poemas em prosa - o que eles têm de peculiar? O ritmo? O uso das imagens? Ou a diferença estaria mais na distribuição do texto na folha, no caso, não em forma de versos? Qualquer que seja o conceito a ser trabalhado, o ideal é que a teoria não venha explicada antes da experiência de leitura; os conceitos são mais bem apreendidos quando inferidos das leituras. Neste sentido está-se ensinando a construir o saber e não meramente decorá-lo.

Outras atividades podem ser realizadas a partir do diálogo com outras artes, como por exemplo, a encenação de poemas, cantar poemas que foram musicados, ilustrar alguns (com desenhos, fotografias, etc.) a partir da escolha e discussão dos alunos, elaborar uma apreciação escrita sobre a poesia do poeta - deter-se num poema, num tema, em aspectos mais gerais - para publicar em blogs, jornais escolares, etc. Há vários documentários sobre Quintana que podem ser 
vistos em sala de aula ou sugeridos, bem como há gravações de poemas pelo próprio poeta, o que sempre se constitui numa curiosidade por parte dos leitores ${ }^{9}$.

Todas essas atividades demandam tempo de convivência com os poemas, o que favorece um conhecimento mais vertical da poesia. Conhecer bem um poeta/poetisa é, por certo, melhor do que passar em revista dezenas de autores sem muitas vezes ler, sequer, um poema integralmente. Por fim, é sempre oportuno alertar que estas sugestões não devem ser aplicadas simplesmente. É fundamental conhecer a turma (seu horizonte de expectativa), dialogar com ela, escolher o melhor procedimento inicial. Dessa entrada dependerá muitas vezes o desenrolar positivo da vivência da poesia.

\section{Conclusão}

Dentre os vários gêneros literários, o poema é, possivelmente, o que melhor favorece o trabalho na sala de aula. Mesmo numa aula de 40 ou 50 minutos é possível realizar várias leituras de um mesmo texto, discutir questões suscitadas - de ordem temática, formal, interdisciplinar. No entanto, insiste-se na abordagem historiográfica que subordina todo texto a determinado estilo de época. Os acervos do PNBE que têm chegado às escolas poderiam ajudar na mudança desta postura, uma vez que possibilitam o acesso a um número maior de livros. Poder-se-ia, por exemplo, trabalhar com vários poetas e/ou poetisas, dividindo a turma em grupos. Mas sem deixar os alunos soltos, pelo contrário, orientando-os e estimulando-os a lerem os poemas e, a seguir, a compartilhar suas descobertas com os colegas.

As sugestões apontadas para o trabalho com a antologia de poemas de Mario Quintana podem servir como um caminho a ser seguido. Cada poema, como lembra os ensinamentos da estilística, pede uma entrada particular. E, em consonância com as reflexões sobre a recepção dos textos, cada leitor preenche os vazios do texto a partir de uma perspectiva pessoal. Talvez fosse de bom

9 Destacamos apenas três pequenos vídeos sobre o poeta, com destaque para a leitura que o ator Antônio Abujamra faz de um poema. São eles:

$O$ anjo poeta (http://www.youtube.com/watch?v=rTBgJvsg89g);

Antônio Abujamra declama Mario Quintana

http://www.youtube.com/watch?v=473CuobszBc\&list=TLP6NeLTlcTlHKzs8uyvtAifpqUQXi3 $\mathrm{KAO})$;

Mario Quintana por Emílio Pacheco

(http://www.youtube.com/watch?v=rfxAopMFnEI\&list=TLP6NeLTlcTlHKzs8uyvtAifpqUQXi 3KAO). 
grado que o PNBE, além de enviar as obras, pudesse também indicar propostas metodológicas que poderiam ser retomadas ou modificadas pelos professores de acordo com sua realidade. Mas nenhuma alternativa metodológica chega a termo se antes de tudo o professor/leitor não crer na máxima de Quintana em seu poema "Aula inaugural" (1988):

Fora do ritmo só há danação.

Fora da poesia não há salvação.

A poesia é a dança e a dança é alegria.

\section{REFERÊNCIAS}

AGUIAR, V. T.; BORDINI, M. da G. Literatura: a formação do leitor - alternativas metodológicas. Porto Alegre: Mercado Aberto, 1988.

ALVES, J. H. P. A representação do tempo na poesia de Mário Quintana. Tese (Doutorado em Literatura Brasileira) - Faculdade de Filosofia, Letras e Ciências Humanas - Universidade de São Paulo. São Paulo, 2000.

BITTENCOURT, G. N. S. O ensino da literatura no $2^{\circ}$. Grau: ótica do professor e do aluno. Gragoatá, Universidade Federal Fluminense (UFF), Niterói - RJ, n. 2, 1997.

BRASIL, Orientações curriculares para o ensino médio. Linguagens, códigos e suas tecnologias. Brasília: MEC/SEB, 2008. v. 1.

COLOMER, T. Andar entre livros: a leitura literária na escola. Trad. Laura Sandroni. São Paulo: Global, 2007.

COSSON, R. Letramento literário: teoria e prática. São Paulo: Contexto, 2006.

DALVI, M. A.; REZENDE, N. L.; JOVER-FALEIROS, R. (Org). Leitura de literatura na escola. São Paulo: Parábola, 2013.

GULLAR, F. A luta corporal. In: . Toda poesia. 1950-1980. Rio de Janeiro: Civilização Brasileira, 1980.

LEITE, L. C. de M. Invasão da catedral: literatura e ensino em debate. Porto Alegre: Mercado Aberto, 1983.

LINS, O. Do ideal e da glória: problemas inculturais brasileiros. São Paulo: Summuns, 1977. 
MALARD, L. Ensino de Literatura no $2^{\circ}$ grau: problemas \& perspectivas. Porto Alegre: Mercado Aberto, 1985.

PAIVA, A. (Org.). Literatura fora da caixa: o PNBE na escola - Distribuição, circulação e leitura. São Paulo: Editora da UNESP, 2012.

PAIVA, A.; SOUZA, R. J.; CORRÊA, H. T. (Org.). Literatura e ensino médio: acervos, gêneros e práticas. Campinas: Mercado Aberto, 2011.

PINHEIRO, H. Literatura no ensino médio: uma hipótese de trabalho. In: DIAS, L. F. (Org.). Texto, escrita, interpretação: ensino e pesquisa. João Pessoa: Ideia, 2001.

. Reflexões sobre o livro didático de literatura. In: BUZEN, C.; MENDONÇA, M. Português no ensino médio e formação do professor. 2. ed. São Paulo: Parábola, 2006.

QUINTANA, M. Os melhores poemas de Mario Quintana. 4. ed. Seleção de Fausto Cunha. São Paulo: Global, 1988.

. Espelho mágico. In: Poesias. 8. ed. São Paulo: Globo, 1989.

REZENDE, N. L de. O ideal de formação pela literatura em conflito com as práticas de leitura contemporâneas. In: SANTINI, J. (Org.). Literatura, crítica, leitura. Uberlândia: EDUFU, 2011.

ROCCO, M. T. F. Literatura/ensino: uma problemática. São Paulo: Ática, 1981.

SOUSA, P. F. de. Poesia, ensino e formação de professores: vivência com vozes da lírica feminina. Dissertação (Mestrado) - Programa de Pós-Graduação em Linguagem e Ensino, UFCG, Campina Grande, 2013.

TARDIF, Maurice. Saberes docentes e formação profissional. 11. ed. Tradução: Francisco Pereira. Petrópolis, RJ: Vozes, 2010.

Texto recebido em 28 de abril de 2014.

Texto aprovado em 05 de maio de 2014. 
